\title{
The Social World of Seafarers. A Sociological Research in Central Italy
}

\author{
Esposito Maurizio \\ Department of Human, Social and Health Sciences, University of Cassino and \\ Lazio Meridionale, Italy \\ Email: m.esposito@unicas.it
}

Received June $11^{\text {th }}, 2013$; revised July $11^{\text {th }}, 2013$; accepted July $18^{\text {th }}, 2013$

\begin{abstract}
Copyright (C) 2013 Esposito Maurizio. This is an open access article distributed under the Creative Commons Attribution License, which permits unrestricted use, distribution, and reproduction in any medium, provided the original work is properly cited.
\end{abstract}

\begin{abstract}
Background: This article analyzes the social world of seafarers, with the aim of crossing the boundary defining the field of social sciences and entering the area of knowledge, where, to paraphrase Marcel Mauss, scientists argue for a place. Methods and Instruments: The research is based on an empirical study carried out at port authorities, fishermen's cooperatives and fish markets in a few regions of central Italy during a two year period using empirical research methods utilized in fields of sociological knowledge, such as: semi-structured interviews, talks and informal conversations. The qualitative research was conducted through Computer Assisted Qualitative Data Analysis Software using the software Atlas.ti. Our attempt is to study in depth, through an empirical study conducted on a sample of 119 individuals, the heuristic subject on seafarers, in particular sailors and fishermen, specifically from a sociological point of view. The focus is an analysis of the life-worlds of these people in connection with variables such as the socio-economic characteristics of households, the relationship with the primary nuclear family, the element of solitude (in connection with individual feelings like melancholy and nostalgia), the relationship with peers and the crew. Results: From empirical research, it is seen that sailors and fishermen, despite their different local facets, represent a social world characterized by the richness of its material, social and symbolic expressions. The craft of the sea unites them, sometimes creating a subculture absolutely different from that of other populations and subcultures.
\end{abstract}

Keywords: Sociology; Qualitative; Society; Seafarers; Community

\section{Introduction}

A sociologist is a person who has a passionate, inexhaustible, shameless interest for facts regarding men, and Peter Berger wrote in his book Invitation to Sociology (1963): his natural habitat-he continues - is any place where men meet. The sociologist may have an interest for many things, but his dominant interest is for the world of men, their institutions, their history, and their passions.

The most frequent accusation towards social scientists is that they want to be all-round experts, at all costs want to trace back every aspect of daily life to "sociology", whether it is private or public. On the contrary, sociologists really try to subdivide the discipline, sometimes creating insurmountable barriers within their own fields of study. From our point of view, presented in this article, fishing is not just a means to procure food or to make a profit; a world of images, representations and rites rotate around fishing, which have inspired great poets and novelists over the centuries, have created a well-rooted community in society, with its own customs and traditions. Sociology, therefore, can not in any way neglect these elements; indeed, by moving away from single statistical data, and entering the world and core of sea life, we can rightfully speak of sociology of fishing.

\section{The Relation between Sociology and Sea Life}

Over the centuries, in the communities developed on the shores of our country, cultural, historical and highly distinctive dynamics have spread, so that we can indeed speak about the true and real culture of the sea, meant as "representations, feelings, mental life, social character, which nevertheless refer to particular aggregates” (Cipolla, 1997: p. 627). Therefore, in our opinion, life at sea is characterized as a real social behavior: to sail or be a fisherman, one must have a technology and a tenacity, a memory and a high level of collective cohesion, present in communities where "intense relationships between individuals characterized by their mutual identification, union, solidarity, integration" (ivi: 466). Obviously, the hallmarks of this unique community culture are discernible in many interpretative categories all within the culture of the sea, settled over the centuries, where the collective identity of these people has arisen. The unique elements of these cultural categories are: knowledge of the sea, customs, rituals and traditions associated with it, and lastly, its trades. The latter category of interpretation is perhaps more than any other one well suited to be analyzed to thoroughly examine the experience and cultural identity of those living in and for the sea, not only as a simple scenario of natural background, but as a primary source of income for many com- 
munities through work activities, from a sociological view, traceable to specific patterns of life with specific systems of social and cultural relations. The study of these sea trades, such as the fisherman or the sailor, is well suited to identify common and emerging cultural traits within a community that considers the sea its lifeblood (Corsi, Esposito, \& Meglio, 2012).

In our opinion, the sociological study of fishing can follow two lines of research. The first sees the locations of the sea as local communities outside urban areas, with their own rules of life, customs and crafts anchored to tradition but also open to the changes that the post-modern society brings. In sea places, in fact, time seems to have stopped, you can still breathe the smell of a world that seems to look out for the first time to the sounds of modernity. Belonging to a community or a country, for those who live the sea, does not mean belonging to a purely geographical or physical area. The identity of those who live there is lived in symbiosis with their peers, as in the case of Amalfi, an ancient maritime Republic, when on the feast day of its patron, St. Andrea, all the fishermen, young and old, participate in the rite of the simulacrum exposure, to ensure that the fishing of the night is propitious to the new fishing season.

Sociology of fishing must turn its attention to the sea as a place of identity, daily life (Montani, 2000), the sharing of customs and traditions of a community. It is in fact within these social environments that the life-worlds of individuals that live there are built, worlds with a widespread inter-subjectivity which, starting from the authentic values of life, create lasting bonds with the great organized systems. In this manner the life-world of seafarers is connected to the global changes affecting the macro-social areas of the country, with what the sociologist Achille Ardigò, in his successful work, defines "parallel convergences" (1980).

The second interpretative line follows a few paths of modern sociology, in relation to the attention social scientists gave the attitudes and behavior of individuals towards the environment in general and to specific natural resources, such as marine or river water. The entrance of sociology within the international debate on environmental issues was neither simple nor prompt. The problems had to become quite relevant before the subject was given public attention, and in turn, institutional interventions had to be significantly of social importance to attract the attention of sociologists (Pellizzoni \& Osti, 2003: p. 55). Pollution, waste and climate change are only a few of the concerns with which the national and European public opinion have to deal with, characterizing the environment as an "epistemology with an eco-social or global interpretation, that is, including biological and physical elements together with cultural dimensions of conscience within it” (Cipolla, 1997: p. 112). In particular, it is the climate change, more than others, which has a major impact on the marine world. In March, 2009, the FAO presented its Report on the state of world fishing and aquaculture. The fishing sector employs more than half a billion people worldwide. Unfortunately, little is done to implement responsible fishing practices aimed at tackling the on-going climate change. According to the report, in fact, fishing and aquaculture contribute little to climate changes but are significant for greenhouse gas emissions during the fishing, transport, processing and storage phases. This is closely related to the increase in world fish production, which reached a new peak of 143.6 million tons of fish in 2007. The increase in production is due to the aquaculture sector, which currently accounts for $47 \%$ of all fish consumed by humans as food. Production levels in capture fisheries has leveled off and is unlikely to increase beyond current levels. The report also identifies the overcapacity-a combination of too many boats and highly efficient fishing techniques—a key problem affecting fishing (Beck, 1992).

The two views above intend to propose a series of studies associating fishing to sociology. Indeed, overlooking the mere statistical calculation of people employed in the fishing Industries, the marine world presents itself to the social scientist in a double vision: as a community full of values, norms and customs often resisting globalizing lifestyles still constituting an unexplored microcosm, and, as an important ecological issue, presented to the attention of sociological studies of the sector.

\section{Research in the Field: Participants, Methods and Analysis}

Empirical research was carried out at port authorities, fishing cooperatives and fish markets in a few regions of central Italy during a two year period using methods utilized in sociological fields such as: semi-structured interviews, talks and informal conversations.

A sociological type of study can not contemplate a culture taken out of its historical and territorial contexts, thus resulting invalid in a notional and socio-graphic sense. Therefore, we decided to turn the empirical investigation to fishermen and sailors of long voyages (mostly oil tankers and cargo ships). The division of the two professions is not random: without doubt both the sailors and fishermen know the secrets of the sea, but nevertheless there are great differences. The sea of the great expanses of oceans is undoubtedly not comparable to the voyages off the coast, as well as the absence periods from home, which are much longer for the former group than for the latter. Therefore, on one hand, the sea can be the same for both but, on the other hand, different. The interviews to the fishermen were all carried out on the coasts of central Italy, where small-scale fishing and mussel farming is practiced. The interviews with the sailors were done at the shipping and landing of the ports considered.

The subject of this study is not fishing or navigation stricto sensu: our model remains the qualitative analysis of narratives. The method used is therefore part of the micro-sociological view, allowing to grasp, in the everyday life dynamics, the ways the material and symbolic reproduction of individuals takes place in every day life (Ricolfi, 1997).

The qualitative research, conducted through Computer Assisted Qualitative Data Analysis Software using the software Atlas.ti, was based on semi-structured interviews, aimed at investigating mainly the experiences of seafarers in regards to their life and their work, but with a specific intention to explore new themes through their answers. Using the grounded theory model (Glaser \& Strauss, 1967), the text was analyzed from the data and returning back to the text, in order to complete the construction of categories, concepts and relations among them.

Accordingly, during the first stage of analysis there was not an advance plan, which enabled recurrences to emerge from the text and, by extrapolation, development of one or more topics of investigation. The contents were then encoded initially with an open coding, mostly reporting the words of the protagonists; only later were the "quotations" coded for recurrent themes in Code Families, in order to build families of concepts that could address reflections, also through the definition of relationships within the Network themes. 
By crossbreeding the Family Codes, operative Super Codes were derived (by Boolean operators) which enabled us to observe significant relationships.

In reporting the interviews verbatim, the code " $F$ " is for "fishermen" and "S" for "sailors".

Regarding the socio-demographic characteristics of the respondents, the sample is characterized heterogeneously for the number of subjects, their jobs, age and geographical origin; the only absolute consistent data concerns their gender, all being males. There were 119 semi-structured interviews with professional sailors and fishermen, precisely 65 sailors and 54 fishermen, divided in three age groups: 18 - 39, 40 - 55, 56 and over. The majority of respondents, $50.4 \%$, are in the second band, followed by the young ones. The instruction level is mostly the common high school diploma, among which, the nautical institute; it should be noted, however, the high number of people who have no formal education beyond secondary school. It is common that the sailor profession, over the centuries, has always been handed down from father to son; indeed, in this way, the ancient seafaring societies, for example, the Mediterranean with its coastal areas, arose. Important seafaring traditions developed, in fact, on the coasts and in the Aegean islands, in the northern Adriatic, Sicily, in the Gulf of Naples and the coasts of Liguria. It is the productive, social and cultural specialization of these populations that can be defined as the culture of the sea. To date, however, there seems to be a decrease of generational continuity in the professional choice of seamen: $37.8 \%$ of the seamen are fishermen's sons, compared to $58.8 \%$ of men whose father is or was a general worker or a craftsman.

\section{Discussion}

\section{Work at Sea}

The primary focus investigated was the degree of individual satisfaction with their job. From the respondents' answers, a certain degree of overall satisfaction was seen, although there were negative replies also. Summing up the responses to the question “Are you happy with the job you are doing?", indeed the absolute majority (88\%) said yes, including $32.8 \%$ firmly convinced. It is noteworthy to see that the younger ones declare not to be satisfied, which is soon confirmed by the quality data of the answers given in the interviews. Substantial differences between the two professions are not detected: many fishermen still associate sea life with working in the fields, which sometimes appears as a way to enjoy their leisure time, but more often becomes a real double job, as stated also by the French historian Fernand Braudel who wrote in his well-known book on the Mediterranean: "Our fisherman-craftsman, however, does not only live in his boat, among fishing lines and nets. He is also a farming expert, careful, he cultivates his own garden and fields. Therefore, he has two professions, otherwise, how could he and his family live? He is forced to draw an income from both land and sea... Transferred to urban centers, a group of Greek fishermen can not now make ends meet” (Braudel, 1987: p. 35).

If some chose the profession because forced by circumstances, such as unemployment and economic emergencies, many, especially sailors, associate this choice to a personal passion due to the love for the sea, as can be seen from the first coding phase of the descriptive codes:
I really chose it because I love the sea very much, then it is a job that helps you become responsible because it requires a lot of effort and then finally because it is a wellpaid job (Interview 8S).

I chose it for passion, in fact I chose a school like the Nautical Institute, which helped me for this life, it was my passion, because I grew up among boats and nets (Interview 33S).

Some, especially the younger ones, in the absence of work, and not having continued their studies, have somehow been forced to choose this profession, and do not hide their dissatisfaction, with the passing of time, especially for the difficulties and sacrifices they continually face:

Not much because it is sacrificed; I chose it because 20 years ago I did not know what to do, living near the sea, the only alternative was to learn how to fish (Interview 12F).

No, I've never been happy with this job, but it was the only opportunity we had to survive. If I could choose, I definitely would not do it again, I chose it only because it allowed me to make a living for me and my family (Interview 15F).

Only those who are born and live the sea can understand the bond that develops between man and his habitat: this seems to be the leitmotif, beyond the negative conceptions, which is seen from the interviews:

I chose it because we are a race of seamen, it is like an inheritance, as a child we always went to see dad at the port, I was fascinated by that life, the sea was and is my world, it was almost a "heritage", my family has always been a family of fishermen (Interview 3F).

\section{The Boat as a Total Institution?}

Erving Goffman writes Asylums in 1961, a text that becomes a milestone for anyone interested in marginalization issues. Starting from the concept of social organization, which defines a group of places, premises, buildings, constructions where a specific type of activity is regularly carried out, he distinguishes between a total or non total institution: this characteristic is symbolized by the barrier to social intercourse with the outside world, often based on the physical structures of the institution: behind closed doors, high walls, barbed wire, rocks, waterways (Goffman, 1961).

The key concept of this work is that of total Institution. Among the various types of institutions - the author lists fivethere are those established for the sole purpose of pursuing some work like tasks justifying themselves on these instrumental grounds: the ships are part of this category.

This assimilation was most recently repeated by the Polish sociologist Janiszewski, who, in an article in 1993, supports the classification of merchant vessels and fishing boats as total social institutions; life in these contexts is suspended between work demands and family needs experienced by sailors and fishermen, in connection with the contradictions between the fathers' and husbands' duties and responsibilities on board (Janiszewski, 1993).

From the evidence of empirical research carried out by us, the men interviewed, and more specifically the sailors than the fishermen, perceive the boat where they live, work and relate as 
a world apart, a reality in itself, which is affected totally with that insider element typical of the primary "familistic" community type. The crew of the ship, as well as the groups of fishermen (those called paranze in Campania), are contexts that, despite the inevitable internal conflicts, appear as strong and compact externally. These specific conflicts are sometimes mitigated by moments of almost absolute silence, in which "sometimes someone speaks. But almost all the boats were silent, except for the dip of the oars” (Hemingway, 1996: p. 29).

For the seafarers, the paranza is only one of the cases, perhaps the most organic you can ever meet in micro-fishing organizations. However, specific strategies develop in every seafaring organization, regarding relationships within the group as well as with the outside world. Competitiveness, for example, is turned to the outside world, while cooperation and involvement are enhanced within the group, in a delicate balance of roles and relationships. Valued are also courage and determination in work experience accrued over the sea, where prestige and authority are fundamental for the function of leadership, found in different degrees among all crew members, in any case (see Mazzacane, 1989: p. 16).

In the case of sailors, internal compactness adds the characteristic of self-defence to the sense of cooperation, since continued exposure to foreign ports conveys, besides feelings of surprise and curiosity, feelings of discomfort, if not fear and anguish too.

From the descriptive codes of interviews with sailors, there are no particular problems in the relationship on board between the shipmates:

Excellent relations. They're the only friends I have and I can talk about my problems. We are one for all and all for one (Interview 54S).

We have fantastic relationships! We feel a big family and we never make distinction of degrees: we are all friends, because I think when you share many years of work and many experiences of danger, the bonds become more and more close and are therefore fraternal relations (Interview 31S).

Although some respondents emphasize the fact that these bonds are often "forced" to get along with the need to live together a long time and the fact that the shipmates are not freely chosen:

Relations must be necessarily good, since we spend so much time together, but sometimes also occurs nervousness, because often you are nervous because of the distance from the family (Interview 52S).

Relations must be good, you have to sail together months and months, you can not argue. Sometimes it happens, but it lasts a maximum of 5 minutes because we seek to live in the best way (Interview 34S).

The relationship with shipmates is only a working cooperation, but a true friendship can be born; and then we can not argue, because we spend too much time together. I personally talk a lot with all staff, both when we plan a job, and when it comes to politics, to various events. I speak equally with everyone. Let's say that the relations on the ships actually have to be very well together, you have to try to be like a family to work the best (Interview 49S).

If the above elements have somehow confirmed the goffma- nian intuition of ship-total institution combination, this should be reinterpreted in the light of a more open and global worldview of the sea. If the life of the inmates or detainees stands out mostly for its characteristic of temporal indeterminacy, on the contrary, the sailors' voyages are temporary, changeable and free above all, lived in the open air, in contact with worlds away from their own. Moreover, in a total institution, the guidelines are rigidly imposed from above, from a "big brother" who tends to control everything with his longa manus; contrarily, on the boat there is greater cooperation between the crew members, giving rise to a differentiation of social roles, each different, in the pursuit of a collective goal that can be traced in an excellent fishing trip, or trying to save themselves during a storm.

\section{The Sea and the Mainland. Family Relationships}

The deep dividing line between life on land and at sea is described with great narrative effect by Jorge Amado: "He was asleep in a net, which of all things on earth is most similar to a ship, rocking as if it were rocked by the waves" (Amado, 1985: p. 109). The seafarer spends most of his day, and therefore, most of his life, at sea, or in activities connected to his work. In the case of sailors, the time spent at sea is sometimes immeasurable, being offshore for months, or even years; in the case of fishermen in the context of our research a typical day is, counting the time to prepare for fishing, out at sea, auctions and sales, an average time of at least 15 - 18 hours per day. It is therefore obvious that the relationship with the mainland is in both cases extremely marginal and seafarers feel cut-off from the wider community, both in the physical and temporal sense and feel a sense of withdrawal, substantially a "retreat" as Lévinas stated. From the interviews conducted, it is clear that the feeling of resignation emerges, however not considered-as we might expect-as feeling distressed or victimized, but rather as a connotation of a life often emphasized as non-binding and of liberal choice.

Sometimes you get the feeling of being alone, away from the world, from your loved ones, from your land, at the beginning one suffers, but with time the passion and love for the sea heal your wounds. I did choose it for passion, if I could not stand it, I would give it up (Interview 21F).

A lot of sailors are not even recognized by their young children when they go back home, and many fishermen tell us with regret that they have never been able to take their children to school; all this constitutes a reality where, in spite of the current economical guarantees granted as well as the recognition of inalienable rights, the life of the seafarer continues to be a marginal existence, in intra-family relationships and during his leisure time and social activities outside the family. Thus, the theme of temporality is strictly linked to the sailor's and fisherman's professions. Moreover, the periods of those who live the sea go over the simple counting of lunar calendars, they go through stages of life, childhood moments, places of memories, which sometimes shatter like waves on the rocks.

It is, above all, the "time for the family" (Gasparini, 2000: p. 58), which includes the social occasions of each person, such as births, child care, housework, that strongly suffer from the physical distance of those who live the sea. In our research, though the great majority of men interviewed stated they had a good relationship with their wives, more often complained 
about missing their children, the informal conversations with the same people have instead shown a partly discordant reality, especially for the world of sailors.

Regarding the relationship with their wives, on one hand, unity and strength of the couple prevail, while, on the other hand, there is a sense, almost of resignation, in accepting the situation that takes their husbands away for months. There are obviously cases where things do not always go well, or the distance and husband's continuous absence from home cause problems for the couple's life, above all for sailors forced to spend long periods of separation from the family:

It is better now, but two years ago she took a period of reflection and went to live with her mother for about a year, because she no longer wanted to be alone with the child. We talked a lot and now she realized that I can not do otherwise. Our relationship has improved and she is much more serene (Interview 59S).

Wives are not accustomed to the presence of their husbands at home, a presence which upsets the daily routine and makes housework more tiring. The presence of the husband sometimes implies a questioning of the running of the house and the education of the children, two very important tasks which for many months remain under the wife's exclusive responsibility and authority. The fathers do not find in their children what they hoped or expected and at the same time "the children find it difficult to recognize and accept the authority and even the affection of a father who is not involved in their everyday lives” (Giglia, 1989: p. 150).

This is also confirmed by a recent sociological research (Heikell, 2010: pp. 68-70), which attests through the life story of a fisherman's son the perception of the father figure as an outsider, a foreigner, an occasional visitor of the house: the mother and the children take the scene of the family organization as protagonists, while the contribution of the father figure is described as marginal and insignificant: in the end, it was the mother who found the apartment for Robert (the protagonist of the research) for his undergraduate studies, she provided for his basic needs and solved his everyday problems. It is no coincidence that the title of an interesting book on the life of fishermen written by Michelle Thomas in 2003 is called Lost at Sea and Lost at Home.

Therefore, despite the lack of interest in scientific literature on the role of women in the seafarer's life, they have a significant and important role in the economic and managerial sector of the productive and reproductive life of this social world. As rightly stated by Paul Thompson et al. (1983), fishermen depend on the role of women in three areas:

1) Women who work directly at sea as crew members (a minority of cases);

2) Women who have a substantial role in raising (in a physical but also cultural sense) future generations of fishermen;

3) Women who have the task of organizing the home and family life during the man's absence.

Ultimately, the nature of the profession of the fisherman and sailor makes it impossible for the man to actively participate in the domestic life. Very often, the social roles usually belonging to the male figure in these families are covered by the female counterpart, often done skillfully and absolutely essential for the maintenance and economic reproduction and management of resources (Marciniak, 2010: p. 76) .

\section{The Ports, Danger, Loneliness}

Books on travelling by sea and about life on board vessels are numerous, as well as legends and mysteries that sometimes surround this argument passed down by sailors: whole days away from their countries, their families, with rites and work that are repeated regularly every hour with the same cadences and the same precision. In the analysis of our interviews, having to work with a large number of descriptive codes, we proceeded to build "families of codes" that have helped us to build more efficient analytical dimensions. So our respondents, belonging to the sub-sample of sailors, tell us about their days on ships:

Navigation at sea is tough because you go away for a long time. The day starts very early depending on the guard duty and maintenance shift. You work 4 hours and then rest 8 , but in fact you work all day for friends who are in trouble. Sometimes unexpected circumstances happen, such as storms or accidents onboard, but we manage to adapt to every situation. When everything goes well we are able to sleep at night. When something goes wrong and there is a problem with the ship we must stay on guard or fix the ship. Recently I had to be the head boatman. I took care of all the on-board equipment, the watertight doors, fire doors, I did the maintenance work on all these. In addition, there was the on-call service at night, because at night the ship is like it is during the day, nothing changes, it is always under control and supervised (Interview 45S).

Loneliness is without doubt one of the most common feelings for those who work and live the sea. The distance from the family, house and affections, can not be erased in front of the infinite expanse of the sea. From the findings of our research, we can see that the sense of loneliness in the fishermen and sailors is indeed present but not extensively. In many cases the seafarers never feel really alone, because they are with other well-known comrades, often relatives, helping to create a mechanism of belonging to a community (it is no coincidence that the metaphor of community traced by sacred texts is often in reference with the image of a boat). When they have moments of solitude, they think of their family or the mission they have to accomplish. The unwritten rule, to respect and to avoid hetero-destructive reactions related to territoriality, for example, is to be silent, to avoid, as one interviewee told us, to speak only "to let the tongue grasp air". This feeling is described by Hemingway when he says that "it was considered a virtue not to speak at sea unless absolutely necessary. And the old man had agreed and respected that rule. But now he often said his thoughts aloud because there was no one to disturb" (Hemingway, 1996: p. 41). More than a feeling of loneliness, however, one could speak of melancholy, in the case of seafarers. Even in times of joy, in fact, there seems to lurk, almost always, a sense of anguish and abandonment, which, for example, when fishing days are no good you feel sad, and when they are good you worry, in any case, for the uncertain future.

I often think about my children and all the things that I have not been able to give them. In fact, I think about all those things that I could do on the mainland, or simply stay at home with the people dear to me. But then the work takes over. I can think about this a whole day, but at 
the end, you have to concentrate on fishing (Interview 54F).

The situation is different for those working on large vessels, because the timing and mode of work onboard convey more obvious and tangible elements of loneliness, where "silence is so that hearing seems lost" (Comisso, 1988: p. 200). It is the family, however, the theme and most recurrent analytical category in the sailors' thoughts:

We often think of things to do, which are many, but just as often we think about the family, with great melancholy. Many do not feel alone, because they have a lot of friends around, but to me personally it seems like a thousand years since I last saw my family and I often feel bad (Interview 35S).

The results of many studies conducted in various countries on the profession of fishermen and sailors agree in inserting these professions among the ones with the highest number of accidents and deaths. For example, an Australian study published in 2006 on Work Related Maritime Fatalities (O'Connor, \& O'Connor, 2006) has proven that the number of accidents or death at sea continues to increase despite improved security conditions on modern boats. On this issue it seemed interesting to evaluate, through specific questions, the attitude towards weather aversion and risk when "the dead sea does not reflect the stars in its heavy waters" (Amado, 1985: p. 240). The atmosphere that develops between comrades on board when a storm passes without serious consequences is always characterized by a sense of joy and mental relaxation. The interview results attest rather cold and confident attitudes towards storms and tempests. Fortunately nowadays the lives of fishermen, and even more of sailors, are protected by safety rules and regulations that make the usual terror read about in books an old memory. Exploring the analytical categories of "queries" present in our interviews, there are many incidents of danger which the men at sea meet:

Dangers? Yes, many times. While we were at sea in the middle of a storm the engine broke and so we were at the mercy of the waves, without being able to control the boat. It was the worst experience that I had, I was so afraid of not being able to go back home. Luckily, after two days we managed to go back home exhausted and hungry (Interview 1F).

When a sailor arrives at a port unknown to him, an alternate mechanism of social adaptation is activated: if you are alone, fear and distrust prevail more than the desire to explore new places and experience new sensations; if you go out in a group, ports and surrounding areas suddenly become places where to find fun and entertainment that for too long, at sea, have been abandoned. In interviews, the majority of the sailors declared being happy to know and venture into new places, even to get acquainted with new people and cultures. The port, therefore, presents itself not only as a place of departure, but becomes a place of meetings, non-return, greetings, fear of the unknown, or simply landing and anchoring. In this context, the port becomes a stage for the reception of vital worlds, feelings and adventures of seafarers.

\section{Conclusion}

To understand a community, it is essential to grasp the lan- guage surrounding it, identifying in the daily routine, in ritual occasions, in beliefs and values, like in social institutions, the relationship created between the individual and the sociocommunity dimension. In the case of seafarers, we have seen how this relationship can be considered fundamentally important in building a "material" culture of the sea, and in strengthening the sense of belonging to a group, intended as an "eso that is socially recognized" (Cipolla, 1997: p. 1220). From our research it is possible to see how sailors and fishermen, despite their different local facets, represent a social world which is characterized by the richness of its material, social and symbolic expressions. The craft of the sea unites them, sometimes creating a sub-culture, completely different from that of other populations and subcultures. These men share the risks of storms, the religious rites of propitiation and thanksgiving, and they create strong ties of friendship and strongly believe in values such as the family and sense of belonging.

The sea is the background of their existence. For any other person this vast expanse of blue water may represent a holiday, or perhaps a romantic setting; for those who live it and derive their income from it, the sea is life, and you love it just like you love your birthplace, where you were raised and protected. The research clearly shows the close relationship that develops between the sailor/fisherman and the natural environment in which he lives in. Even if fishing techniques or working hours change, even if family ties remain sound and solid, that great blue expanse calls them like an invisible siren, makes them remodel, rebuild and in some cases, strengthens the pieces of the puzzle that makes up the human life-world of the sea, creating a sense of belonging like deep roots that grow and nourish stems, branches, leaves, flowers, fruit (see Groth, 1982).

\section{REFERENCES}

Amado, J. (1985). Mar morto. Milano: Mondadori.

Ardigò, A. (1980). Crisi di governabilità e mondi vitali. Bologna: Cappelli.

Beck, U. (1992). Risk society. Towards a new modernity. London: Sage Publications.

Berger, P. L. (1963). Invitation to sociology: A humanistic perspective. New York: Knopf Doubleday Publishing Group.

Braudel, F. (1987). Il mediterraneo. Milano: Bompiani.

Cipolla, C. (1997). Epistemologia della tolleranza. Milano: Franco Angeli.

Comisso, G. (1988). Gente di mare. Milano: Longanesi.

Corsi, V., Esposito, M., \& Meglio, L. (2012). I mondi sociali degli uomini di mare. Milano: Franco Angeli.

Esposito, M. (2010). L'uomo post-moderno tra deriva psicologista e "cultura della scorciatoia”. In: Bontempi, M., \& Maturo, A., Eds., I confini mobili tra le sfere della vita. Milano: Franco Angeli.

FAO (2009). The state of word fisheries and acquaculture. Roma.

Gasparini, G. (2000). La dimensione sociale del tempo. Milano: Franco Angeli.

Giglia, A. (1989). Il mestiere di navigare: Immagini del lavoro e del territorio nei racconti dei marinai di Monte di Procida. In: Mazzacane, L., Ed., La cultura del mare. Bari: Laterza.

Glaser, B. G., \& Strauss, A. L. (1967). The discovery of grounded theory: Strategies for qualitative research. New York: Aldine De Gruyter.

Goffman, E. (1961). Asylums. Essays on the social situation of mental patients and other inmates. Anchor Books. New York: Doubleday \& Company, Inc.

Groth, G. (1982). Toward a sociology of fishing. Rural Sociologist, IV.

Heikell, T. (2010). Growing up in a seafaring family: Recollecting one's childhood with an absent and present father. Annuals of Marine Sociology, XIX, Gdansk-Szczecin.

Hemingway, E. (1996). Il vecchio e il mare. Milano: Mondadori. 


\section{E. MAURIZIO}

Janiszewski, L. (1993). Seagoin vessel and deprivation of needs. Przeglad Socjologiczny, 40, 181-195.

Marciniak, B. (2010). Women as invisible fishing crew members. Annuals of Marine Sociology, XIX, Gdansk-Szczecin.

Mazzacane, L. (1989). La cultura del mare in area flegrea. Bari: Laterza.

Montani, A. R. (2000). Teorie e ricerche sulle comunità locali. Milano: Franco Angeli.
O’Connor, P. J., \& O’Connor, N. (2006). Work related maritime fatalities. Accident Analysis \& Prevention, 38, 737-741.

doi:10.1016/j.aap.2006.01.004

Pellizzoni, L., \& Osti, G. (2003). Sociologia dell'ambiente. Bologna: Il Mulino.

Ricolfi, L. (1997). L'analisi qualitativa. Milano: Nuova Italia.

Thomas, M. (2003). Lost at sea and lost at home. Cardiff: SIRC.

Thompson, P. et al. (1983). Living the fishing. London: Routledge. 